\title{
O MEMORIAL DO COLÉGIO DOM BOSCO DE PETROLINA-PE (1996-2015)
}

\author{
Jardel Costa Pereira* \\ lattes.cnpq.br/9773257845047826 \\ Rozângela do Nascimento Pereira*** \\ lattes.cnpq.br/7138563924827173
}

\begin{abstract}
Resumo: Há várias formas de escrever a história da educação e da pedagogia. A maneira escolhida e apresentada nesse trabalho é um memorial escolar, que pode ser um instrumento importante onde se encontra documentos reveladores de como era a escola no passado. O manejo de fontes documentais e de arquivo, a consolidação de centro de memória educativos e pedagógicos, são aqui apresentados como uma possibilidade e um local de aprendizado/treinamento de futuros historiadores/pesquisadores; uma prática que pode, unida à teoria, atrair jovens estudantes tanto da área da Pedagogia como também da História. Um outro foco importante também desse trabalho é perceber como um teórico constrói os seus objetos de estudo e de como esses podem ser utilizados pela História da Educação e da Pedagogia.
\end{abstract}

Palavras-chave: Memorial; História; Escola; Memória; Arquivo.

\section{THE MEMORIAL OF DOM BOSCO COLLEGE OF PETROLINA-PE (1996-2015)}

\begin{abstract}
There are many ways to write the History of Education and Pedagogy. The one chosen and presented in this work is a school memorial, a very important instrument, with which one can find documents that reveal how schools worked in the past. This work presents the handling of document and file sources and the consolidation of educational and pedagogical memorial centers as a possibility and a place to learn/train future historians/researches; a practice that may, along with theory, attract young students in Pedagogy and History fields. Another important focus of this work is to note

\footnotetext{
* Doutor em Educação Escolar. Docente na Universidade do Estado de Minas Gerais, UEMG (Brasil). Contato: jardelcostper@gmail.com.

** Mestranda em Educação, Cultura e Territórios Semiáridos na Universidade do Estado da Bahia, UNEB (Brasil). Contato: rozangelaedu@outlook.com.
} 
how a theoretician creates their study objects and how they can be used by the History of Education and Pedagogy.

Keywords: Memorial; History; School; Memory; Files.

Figura 1 - Memorial Dom Bosco. Fonte: Colégio Dom Bosco. 29/03/2015.

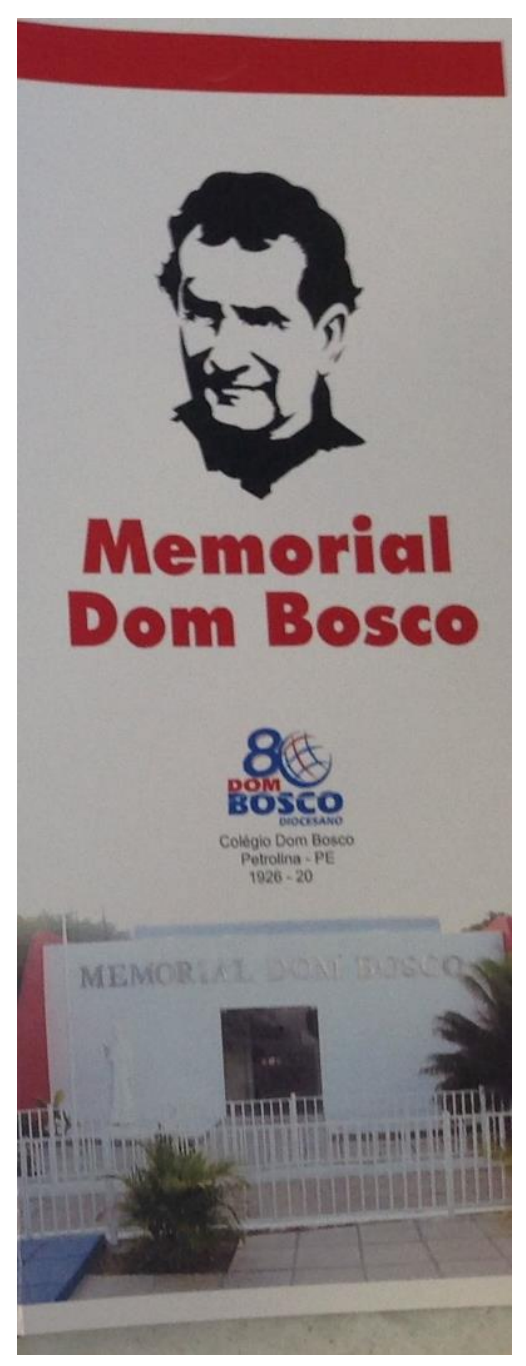

O objetivo desse trabalho é apresentar o $\mathrm{Me}$ morial Dom Bosco, localizado no interior de um colégio privado, vinculado à Diocese de Petrolina, no estado de Pernambuco. Um memorial escolar pode contribuir na reconstrução histórica de uma instituição e preservar a memória escolar, contribuindo para construção da história da educação local.

Num recente trabalho de conclusão de curso de graduação em História, na Universidade de Pernambuco, campus Petrolina, Santos (2015, p. 4344), pesquisador no Memorial Dom Bosco, destacou a importância do memorial para a escrita da história da educação, sendo que certifica que as instituições escolares constituem-se num importante espaço para as pesquisas em história da educação, "porque é neste espaço que se encontra os arquivos produzidos pela própria instituição, dando possibilidade de se analisar esse material e construir uma memória deste espaço".

Na concepção de Maria João Mogarro, referencial teórico importante para esse trabalho:

Os arquivos escolares motivam profundas preocupações relativamente à salvaguarda e preservação dos seus documen- 
tos, que constituem instrumentos fundamentais para a história da escola e a construção da memória educativa. A sua importância tem vindo a ser reconhecida, conduzindo a uma reflexão sobre a sua preservação, as condições de instalação, a organização correcta dos documentos e o acesso às informações que nele estão contidas. Os arquivos escolares constituem o repositório das fontes de informação diretamente relacionadas com o funcionamento das instituições educativas, o que lhes confere uma importância acrescida nos novos caminhos da investigação em educação, que colocam estas instituições numa posição de grande centralidade para a compreensão dos fenômenos educativos e dos processos de socialização das gerações mais jovens. (MOGARRO, 2006, p. 71).

Investigar a importância do acervo do Memorial Dom Bosco e a sua contribuição para o contexto social, cultural e educacional da cidade de Petrolina e região se torna relevante, pois nada ainda foi feito nesse sentido. Torna-se, portanto, um problema e um desafio para vários historiadores da educação, como descrito por Mogarro (2006, p. 79):

Os historiadores da educação só recentemente se têm vindo a ocupar da arqueologia material da escola, dando atenção aos silêncios da história do ensino e superando o esquecimento da intrahistória da escola e da especificidade própria das instituições educativas.

São poucas as escolas no Brasil, e até mesmo em vários países, que contam com um local específico para guardar e preservar a sua arqueologia escolar. Não é o caso do Colégio Dom Bosco, em Petrolina, pois além de possuir um memorial, a sua idealizadora era atuante como diretora, quando no início do projeto. Um outro desafio é lidar e interpretar esse presente tão real, onde caem por terra as especulações, as interpretações e as deduções, valorizando seus propósitos e intenções.

Nessa direção, encontra-se também o pensamento de Mogarro, que ao escrever sobre uma realidade dos arquivos escolares de Portugal, acena para um campo geral da história da educação que vem se renovando, seja por 
meio de novas abordagens, novos locais, novos métodos de pesquisa e claro, velhos e novos desafios ${ }^{1}$ :

Situamo-nos numa zona de fronteira, de cruzamento, das novas perspectivas da história da educação, da história cultural, da história social e também das ciências da educação. Assiste-se a uma renovação das problemáticas teóricas e de uma reinvenção dos terrenos de pesquisa, das fontes de informação, das práticas de investigação e do apetrechamento metodológico, em que a perspectiva historiográfica se afirma face às antigas abordagens de matriz essencialmente sociológica. A afirmação de uma história que se reclama de um pensamento cultural crítico estabelece uma agenda de diálogo entre as preocupações do presente e as realidades do passado, num esforço de compreensão em que se interrogam estas últimas para alcançar a inteligibilidade dos tempos presentes. (MOGARRO, 2006, p. 79).

Entender um arquivo escolar, sua lógica de sua construção e organização, a exposição de sua materialidade, a concentração em alguns atores sociais ou até mesmo da negligência de outros, as suas intenções explícitas ou implícitas, é poder, no aqui e agora, dar sentido real - e não ilusório - do que vem sendo feito e realizado na preservação da história da escola. Por isso, o projeto desenvolvido na Universidade de Pernambuco tem valorizado a memória viva, atual e presente, por meio de depoimentos orais, dentre outras formas de preservação da memória. Muito se tem perdido de nossa história por causa da dependência de documentos escritos, esquecendo-se de que, quando o documento não existe, os relatos podem preencher essas lacunas.

Este trabalho vincula-se ao Grupo de Estudos e Pesquisas sobre Educação Escolar e não Escolar no Sertão Pernambucano (GEPESPE), vinculado ao NEPHEL - Núcleo de Estudo e Pesquisa em História Educação e Lin-

\footnotetext{
${ }^{1} \mathrm{O}$ mesmo trabalho realizado no Colégio Dom Bosco foi proposto a ser realizado numa outra instituição privada confessional de Petrolina, mas não se obtive o mesmo êxito, pois não deram resposta da possibilidade ou impossibilidade de realizá-lo. Essas atitudes impedem que outros dados sobre a história da educação sejam escritos, ficando assim incompleta outras partes do sistema educacional a ser pesquisado.
} 
guística da Universidade de Pernambuco (UPE). Por meio de um projeto de preservação e recuperação de documentos trabalhou-se no Memorial Dom Bosco de maneira interventiva e de forma interdisciplinar entre os Cursos de Pedagogia e de História.

O Memorial Dom Bosco foi fundado no dia 14 de agosto de 1996 por Terezinha Teixeira Coelho, diretora do Colégio Dom Bosco, com o intuito de conservar a memória da instituição, objetivando preservar a história da educação local.

Terezinha Teixeira Coelho ${ }^{2}$ foi coerente com o seu ponto de vista sobre o memorial e a sua documentação, tendo permitido a intervenção dos historiadores no acervo, como também fornecendo todo o material necessário para conservação de determinadas fontes. Antes de deixar a direção do Colégio Dom Malan, após 41 anos de exercício dessa função, concedeu uma entrevista e convidou Rozângela do Nascimento Pereira, participante do GEPESPE, para participar de um programa na Rádio Rural da Diocese de Petrolina, onde falou do projeto, apresentando-a com as seguintes palavras:

[...] fez pesquisa no Dom Bosco que é, acredito, o centro de registro importante da história de seu povo, história da educação da Diocese de Petrolina, e não somente da Diocese pois o Colégio Dom Bosco faz parte da história da cidade, está interligado. Nosso obrigada. Lá no memorial, as pessoas devem procurar conhecer mais, visitar e ver o acervo importantíssimo que tem para reconhecer o valor que a nossa Diocese tem sobre o papel da educação, quantos passaram... quantos que foram... Na pessoa de Dom Malan, que foi o grande idealizador desse centro cultural que está localizado na Rua

${ }^{2}$ A Diretora do Colégio Dom Bosco, Teresinha Teixeira Coelho, teve e tem uma atuação importante na cidade de Petrolina PE: "Coordenadora da Fraternidade Cristã dos Deficientes, Secretária da Sociedade Pró-Menor, Secretária da Equipe de Coordenação da Diocese de Petrolina; Secretária do Conselho Diocesano de Pastoral; Vice-Presidente do Conselho Municipal de Defesa das Crianças e Adolescentes; Conselheira da AECPernambuco; Representante Regional do Sindicato de Estabelecimentos de Ensino do Estado de Pernambuco; Vereadora entre 1993 e 2004" Sua atuação como diretora da instituição encerrou-se em dezembro de 2015, sendo que ocupou o seu cargo o Pe. Antônio Moreno, doutor em Educação. Disponível em: http://www.domboscopetrolina. g12.br/?page_id=1817). Acesso em: o8 jan. 2016. 
Coronel Amorim, que só fez história, só fez bem para cidadãos e cidadãs e que hoje a gente aplaude. [...]. Obrigado pelo grande trabalho que vocês fizeram lá no Colégio Dom Bosco, lá no memorial. (Entrevista realizada na Rádio Rural, 19/12/2015. Disponível em: http://am730.com.br. Acesso em: 06 mai. 2017).

Segundo observa Teresinha Teixeira Coelho, em entrevista realizada aos 17 de dezembro de 2015, por Rozângela do Nascimento Pereira, o motivo que a levou a fundação do Memorial Dom Bosco foi o seguinte:

Quando assumi a direção do Colégio Dom Bosco, eu pensei muito em como registrar essa história. Assumi em 1976 e então as conquistas estavam acontecendo sempre no colégio D. Bosco, com trabalho dos alunos, com troféus, com informações, por ocasião dos 70 anos do colégio Dom Bosco, eu disse: vai ser este ano, porque eu aprecio muito a cultura, e pra mim o memorial é um elo de cultura para o povo, e o povo sem memória é um povo sem história, e não comportava mais na minha sala colocar os troféus, os registros importantes da história do colégio D. Bosco, então eu pensei, e hoje está o Memorial D. Bosco com um acervo muito positivo, muito bom, que tem como objetivo os alunos conhecerem a verdadeira história do D. Bosco e a comunidade também, porque o D. Bosco pertence à comunidade é um colégio que não tem dono, ele é da comunidade de Petrolina (COELHO, 2015).

No parecer da diretora fica explícito a função que ela apresenta para um memorial e especificamente para o escolar: público, ou seja, aberto a todos da comunidade e fomentador de cultura, trazendo informações e conhecimento, inserindo, assim, a escola na vida do povo da cidade e trazendo para o memorial a população petrolinense, pois muitos se veem ali representados em seus pais, filhos, netos e conhecidos, que fizeram a trajetória escolar no Colégio Dom Bosco.

A própria arquitetura do memorial apresenta essa lógica de abertura à comunidade, sendo o prédio separado do local onde funciona a escola e bem de frente do portão principal, sendo que se localiza mais facilmente a sua entrada do que a porta principal do recinto escolar. 
Teresinha Teixeira Coelho nasceu aos 22 de novembro de 1944, sendo que tinha 52 anos quando inaugurou o Memorial Dom Bosco, tendo uma formação na área de Humanas, que lhe forneceu esse olhar diferenciado como diretora de uma instituição escolar, organizando a documentação da escola para a comunidade:

É licenciada em Letras pela Faculdade de Formação de Professores de Petrolina e pela Faculdade de Filosofia, Ciências e Letras de Caruaru (PE), onde também concluiu o curso de Pedagogia (1978). Ex-professora e coordenadora da rede oficial de ensino da escola Alfa Polivalente e do Colégio Estadual de Petrolina, por seu trabalho e dedicação às grandes causas, vem assumindo a liderança em diversas instituições, imprimindo qualidade e dinamismo aos seus projetos. (Disponível em: http://www.domboscopetrolina.g12.br/? page_id=1817. Acesso em: 08 jan. 2016).

Ao ser questionada sobre a relação memorial e comunidade e de como ocorre um aproveitamento do acervo escolar, Teresinha Teixeira Coelho acrescentou:

Ele é aproveitado para as pesquisas; quase todos os trabalhos que os professores encaminham para os alunos. Por exemplo, para análise da história do fundador do colégio, Dom Malan, há registros importantes sobre sua vida e de outras personalidades; sobre a história geral do Colégio D. Bosco; também de personalidades da cidade de Petrolina e da região. (COELHO, 2015).

O memorial está localizado dentro do Colégio Dom Bosco. De acordo com a monografia desenvolvida por Santos (2015), a instituição educativa foi fundada aos 18 de outubro de 1926 pelo bispo D. Malan ${ }^{3}$ e iniciou suas

3 Dom Malan de Antonio Santana Padilha nasceu em dezembro de 1862, de origem francesa e estudou o curso secundário e teologia em Paris. Entrou para a Congregação Salesiana em 1884, aos 22 anos, fazendo os votos perpétuos no ano seguinte. Veio para a América em 1889, instalando-se em Montevidéu (Uruguai), ordenando-se em 28 de outubro de 1889 (...). Em 1894, segue para Mato Grosso (...). Dedicado e empreendedor, ganhou notabilidade por sua obra apostólica nos sertões indígenas mato-grossenses. Em 1914 era sagrado em São Paulo, como Prelado de Araguaia e Bispo Auxiliar de Amisso (...)." (Cf. CARVALHO, C. Petrolina: entre as cinzas do passado e os albores do porvir. 
matrículas para seu funcionamento no dia 15 de março de 1927, tento como primeiro diretor o Padre Ezequiel Fraga, da Congregação Salesiana.

No início da sua história, o colégio Dom Bosco era uma instituição que se dedicava somente à formação de crianças e de adolescentes do sexo masculino. Em 1946 foi classificada pelo Ministério da Educação e Cultura com 1.783 pontos em deferência à sua construção moderna, de aspecto agradável, e ao alto nível de educação no Nordeste, atendendo a todos os requisitos do ensino de $1^{\mathrm{a}}$ e $2^{\mathrm{a}}$ ciclo daquela época (QUEIROZ, 1983, p. 169). Dom Malan:

(...) fez o palácio episcopal, construiu casas perto da matriz, terminou a construção do hospital D. Malan, que foi iniciado por D. Cardoso, trouxe as salesianas para dirigirem o Colégio Nossa Senhora Auxiliadora e criou o Colégio D. Bosco. Isso incentivou o progresso da cidade, muitas pessoas vieram de cidades circunvizinhas para pôr seus filhos para estudar e, paralelamente, a cidade começou a se desenvolver, tudo aumentou, tudo cresceu e continuará crescendo. (BRITO, 1995, p. 272).

Com a criação dos dois colégios pelo bispo, acredita-se na sua significativa contribuição para com a cidade de Petrolina, e em especial do que diz respeito à educação:

[...] Foi também pelas mãos do grande pastor Dom Antônio Maria Malan que Petrolina ganhou, em 18 de outubro de 1926, uma das instituições que mais a enobrece. Fundou o Colégio Dom Bosco, na certeza de que a sua criação transformaria as gerações para o exercício de importante papéis que a história lhes reservaria. Exemplo magnânimo de dignidade no tratamento à educação, esta escola escreveria uma das mais generosas páginas da história educacional do Sertão Nordestino. (MEMORIAL DOM BOSCO. s/d, s/p. Documento digitalizado aos 26/03/2015).

apud SANTOS, s/d, p. 17). Dom Malan tomou posse como primeiro bispo da Diocese de Petrolina em 15 de agosto de 1924, vindo a falecer sete anos depois. (Disponível em: http://www.diocesedepetrolina.org.br/ler.asp?id=12. Acesso em: 14 fev. 2017. 
Na década de 1930, o colégio Dom Bosco contava com os cursos primário, admissão e ginasial. Seu corpo discente era formado por 65 alunos externos e 14 internos. Seu quadro de professores era composto por: Padre João Leal, Osmar Novais, Manoel de Paiva Neto, Sebastião Ferraz e os Drs. Epaminondas C. Albuquerque e Humberto Costa (BRITO, 1995, p. 259).

Outro personagem de destaque da história do colégio Dom Bosco foi o Padre Manoel de Paiva Neto, que foi professor e também diretor do colégio. Durante 33 anos prestou serviços a essa instituição de ensino. O colégio Dom Bosco tem uma grande importância para a região, pois muito alunos frequentaram a instituição, sendo essa história retratada no acervo de seu memorial.

Para preserva-

Figura 2 - Lista de ex-alunos. Fonte: Memorial Dom Bosco. Petrolina PE. 28/03/2015.

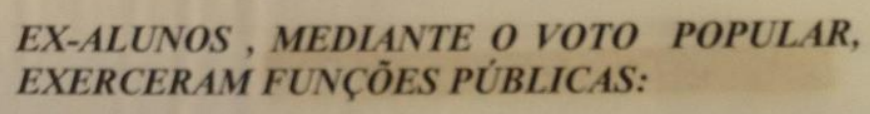

Dr. José de Souza Coelho - Vereador, Prefeito Dr. Geraldo de Souza Coelho - Vereador, Prefeito, Deputado Estadual Dr. Augusto de Soura Coelho - Vereador, Prefeito Diniz de Sá Cavalcanti - Vereador, Prefeito, Deputado

Dr. Fernando Bezerra Coelho - Deputado Estadual, Deputado Federal, Prefeito

Otomar Soura Pinto - Governador

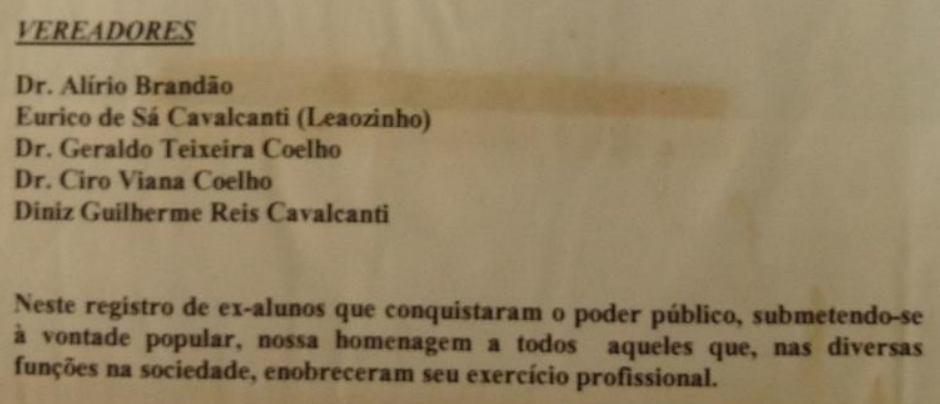

IEREADORE

Eurico de Sá Cavalcanti (Leaozinho)

Dr. Geraldo Teixeira Coelhe

Dr. Ciro Viana Coelho

Diniz Guilherme Reis Cavalcanti

Neste registro de ex-alunos que conquistaram o poder público, submetendo-se
à vontade popular, nossa homenagem a todos aqueles que, nas diversas funções na sociedade, enobreceram seu exercicio profissional.

ção histórica, a manutenção do arquivo é de suma importância para a construção da história local. Esse trabalho retrata a importância que essa instituição teve no processo de escolarização de meninos e moças, em um momento que Petrolina ensaiava, ainda, os seus primeiros passos no cenário educacional, e em um período marcado pela presença de uma política ainda 
baseada nos moldes do coronelismo. É nesta perspectiva que os arquivos escolares têm tido uma grande importância para o campo de pesquisa em história da educação. A análise desta documentação fornece elementos significativos para a reflexão sobre o passado da instituição, das pessoas que a frequentaram, das práticas que nela circularam e, mesmo, sobre as relações que estabeleceram em seu entorno.

O memorial é relevante para a memória escolar dos alunos que estudaram na instituição e para aqueles que ainda estudam, por ter seus regis-

Figura 3 - Boletim Escolar: Ginásio Dom Bosco.

Fonte: Memorial Dom Bosco. Petrolina PE. 26/03/2015.

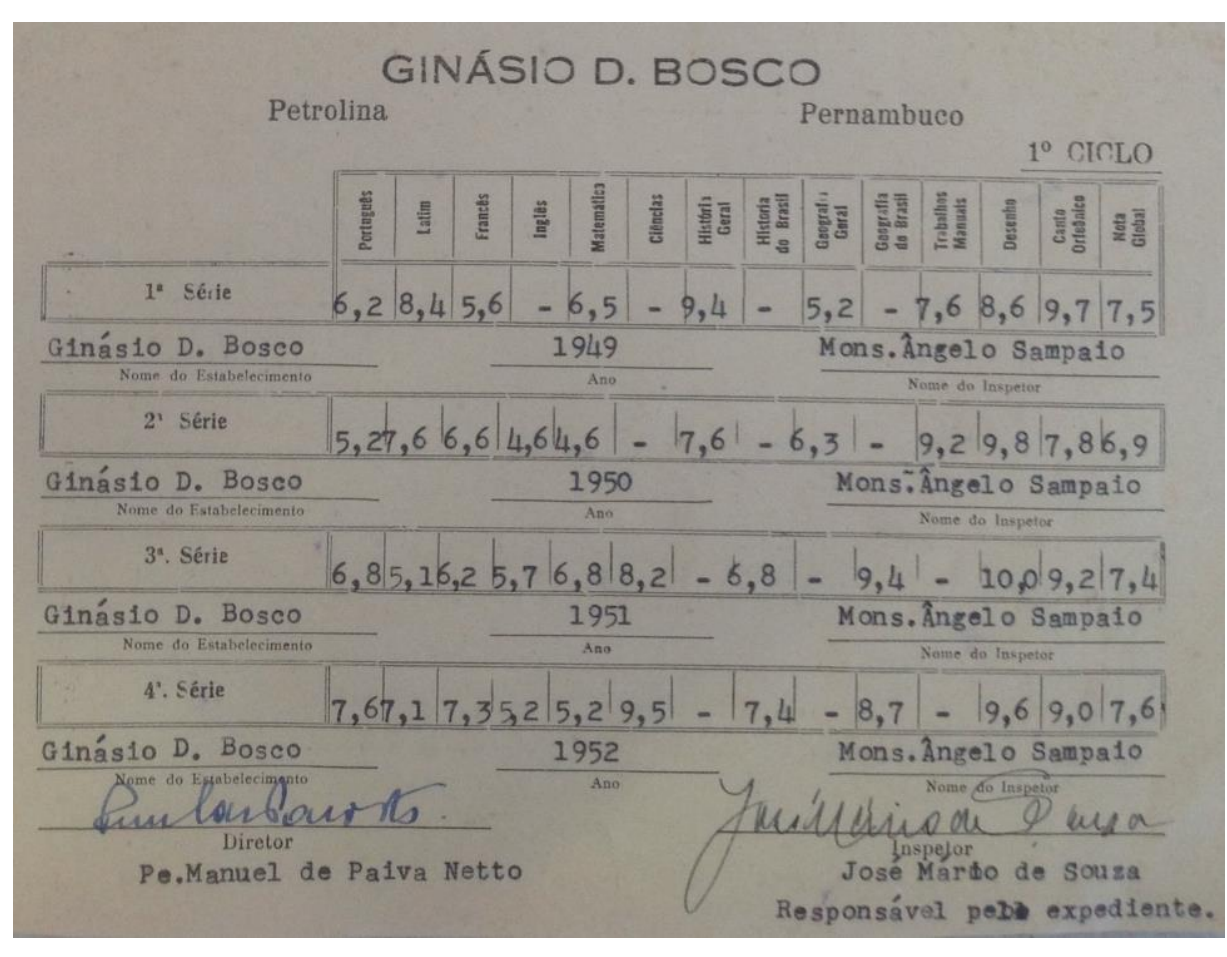
tros preservados de forma adequada num espaço privilegiado da história da educação local. O trabalho realizado no Memorial Dom Bosco, pela equipe de estudantes e professores da Universidade de Pernambuco, constou no levantamento, na limpeza, numa nova organização e na catalogação dos documentos encontrados nesse memorial. O processo de higienização envolveu a utilização de pincéis, o uso de máscaras e luvas.

Após esses procedimentos, teve início o levantamento do material com registro dos seguintes dados: quantidade de documentos, origem, tipo, condições de uso, ano, informações básicas, informações adicionais finali- 
zando com a digitalização e catalogação. Foram encontrados documentos como: correspondência de órgãos públicos, diário oficial da época, documentos de fundação da escola, boletins escolares de alunos, testamento de doação do padre Manoel de Paiva Neto (um dos diretores da escola), fotos da primeira formatura da escola em 1927, entre outros.

As atividades foram desenvolvidas no período de março a outubro de 2015. As estratégias e formas desse procedimento serão apresentadas como modelo que poderá ser seguido por outras instituições educativas da região, tanto para a formação de novos pesquisadores/historia-

Figura 4 - Organização e tratamento de documentos. Fonte: Memorial Dom Bosco. Petrolina PE. 16/03/2015.

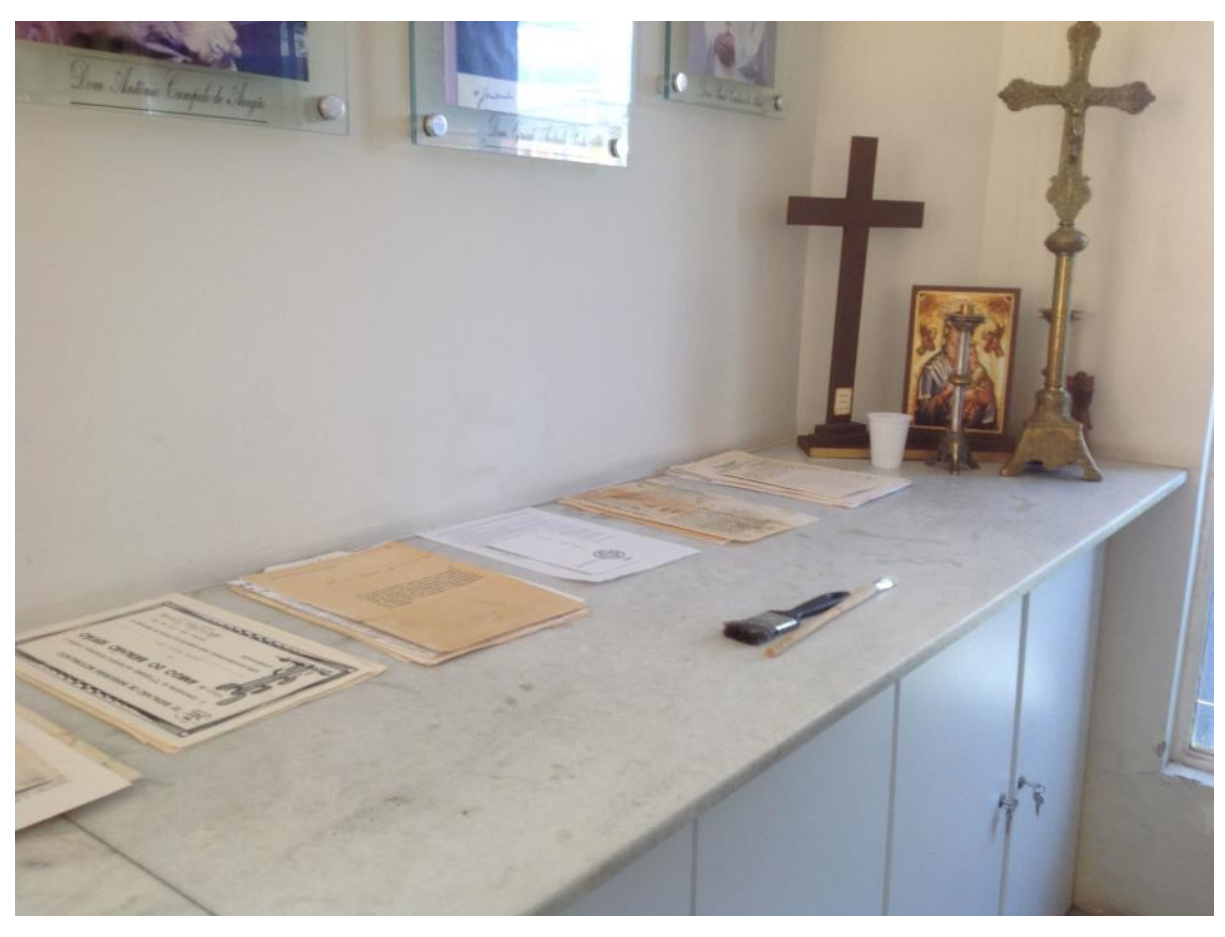
dores, quanto na valorização e no resgate da importância desses memoriais.

O contato com o acervo escolar possibilita a percepção sobre a dimensão do potencial de seu trabalho. Alguns estudos já indicam que na legislação brasileira há um suporte para que os acervos escolares sejam devidamente preservados e organizados, favorecendo assim a pesquisa científica (CARVALHO, 2008). Sobre o caráter jurídico, Medeiros (2004), ressalta que o arquivo escolar se mostra também a partir da figura do pesquisador como facilitador para a pesquisa científica, e que é um direito da comunidade possuir arquivos organizados. 
Conjunto de documentos produzidos ou recebidos por órgãos públicos, instituições de caráter público e entidades privadas, em decorrência do exercício de atividades específicas, bem como, pessoa física, qualquer que seja o suporte da informação ou a natureza dos documentos. [...] o arquivo escolar será o conjunto de documentos produzidos ou recebidos por escolas públicas ou privadas, em decorrência do exercício de suas atividades específicas, qualquer que seja o suporte da informação ou a natureza dos documentos. (MEDEIROS, 2004, p. 1).

Por conseguinte, o autor indica que estes acervos são patrimônio de interesse público e devem ser protegidos por lei: "as escolas particulares exercitam a liberdade de ensino, mas exercem múnus público, pois para isso são autorizadas ou reconhecidas" (MEDEIROS, 2004, p. 1). Apesar da obrigatoriedade da preservação da documentação da escola pela legislação, observa-se ainda um descaso com vários aspectos da preservação destes, necessitando assim de um olhar mais detido para essas fontes escolares e uma gestão apropriada para a sua preservação:

Para a democratização da pesquisa e do conhecimento, para a produção de saberes, os pesquisadores da História da Educação precisam elaborar propostas, exigir o cumprimento do princípio de franqueamento de documentos à consulta, que só poderá ser otimizado com acervos bem organizados. [...] Não existir arquivos organizados com lugar para a pesquisa é descumprir o princípio legal. (MEDEIROS, 2004, p. 9).

Questões como técnicas de arquivamento, de conservação e manuseio do material dos acervos são enfatizadas por Vidal (2007), mostrando que este aprendizado poderá trazer um maior envolvimento da comunidade e a ampliação da noção de documento escolar:

Durante este processo aprendiam a respeitar o patrimônio cultural e arquivístico e compreendiam o significado da educação para a cidadania. [...] O acompanhamento do desenrolar do projeto deixava evidente os ganhos que a atividade trazia para a formação de alunos e professores. O envolvimento que demonstravam tanto nas tarefas mais manuais do arquivamento quanto nas mais intelectuais 
da análise documental da documentação atestava a proficuidade da iniciativa. No entanto, os ganhos não se circunscreveram à sensibilidade destes sujeitos. Ao ser organizado pelo corpo docente e discente, o arquivo suscitou o interesse de toda a comunidade escolar que passou a doar documentos para o acervo compondo o Centro de Memória. (VIDAL, 2007 p. 63).

Sobre a ampliação dos tipos de documentos, Sanfelice (2005) afirma que as novas abordagens históricas trouxeram a utilização das fontes mais variadas como fotos, cadernos, mobiliários, plantas, prédios, o que possibilita a exploração de vários olhares sobre o trabalho, mas que deve estar sempre levando em consideração as perguntas pertinentes para se apropriar dos tipos de fontes disponíveis. Ressalta, ainda, a importância de um empenho maior para se criarem condições objetivas para uma política de preservação das fontes históricas escolares, para que, assim, avance o campo da pesquisa nessas instituições.

\section{Considerações finais}

Percebeu-se por esse breve texto que houve por parte da instituição mantenedora do Memorial D. Bosco uma preocupação em criar um espaço específico para preservar os documentos históricos da escola - entre eles fotografias, jornais, ofícios, troféus, móveis e etc. A organização do acervo foi feita, um primeiro momento, sem nenhum cuidado com a preservação dos documentos antigos, arquivando-os em pastas com plásticos que estavam se deteriorando devido as altas temperaturas da região.

Com a intervenção adequada, os documentos foram envoltos em papel manteiga e receberam uma nova catalogação para facilitar a sua localização e retirada, como também todo o acervo foi digitalizado e informatizado. Na finalização do projeto, foram entregues cópias digitalizadas do acervo, e o mesmo foi apresentado à comunidade acadêmica - docentes e discentes em seu novo formato de catalogação e de organização das fontes. 
O trabalho no Memorial Dom Bosco remete a uma reflexão da importância da preservação de documentos escolares, dos objetos que compõem a sua história. Quando se conhece a história do seu lugar, dos personagens que fizeram parte da construção da cidade, valorizam-se, de fato, suas instituições.

$$
\text { * } * *
$$

\section{Referências}

BRITO, A. C. F. Leal, Ygor Barros. Jornal Pharol: apontamentos para a Modernização em Petrolina. 1915-1920. Petrolina: UPE, 2012.

BRITO, M. C. S. Petrolina. Origem, fatos, vida, uma história. Petrolina: Tribuna do Sertão, 1995.

CARVALHO, J. G. M. História, trabalho e educação profissional no Brasil (EPDB-Poços de Caldas-MG). Dissertação de mestrado (Educação). Universidade Estadual de Campinas, Campinas, 2008.

CAVALCANTE, C. Dom Malan, ícone de fé e trabalho. Olinda: Livro Rápido-Elógica, 2009.

. Teresinha Teixeira Coelho. Uma história de fé, educação e trabalho. Petrolina: Casa da Imprensa, 2010.

DOM BOSCO DIOCESANO. 85 anos. Edição comemorativa. Colégio Dom Bosco: Petrolina, 2011.

LIMA, A. C. A Influência da Igreja Católica no desenvolvimento do município de Petrolina-PE, de 1920 a 1940. Petrolina, UPE, 2009.

MEDEIROS, R. H. A. Arquivos escolares: breve introdução a seu conhecimento. Revista HISTEDBR, n. 14, 11 p., 2004.

MOGARRO, M. J. Arquivos e educação: a construção da memória educativa. Sísifo. Revista de Ciência da Educação, n. 1, 2006.

QUEIROZ, E. A Escola. Um Rio, Uma Cidade, Uma Escola. Recife, Norcópia, 1983.

ROCHA, H. Q. Estou presente, Petrolina! Editora Bagaço. Recife, 2006. 
SANFELICE, J. L. História das instituições escolares e gestores educacionais. In: BITTENCOURT, A. B.; Oliveira Jr., W. M.; Estudo, pensamento e criação. Campinas: Graf. FE, Livro II, 2005.

SANTOS, J. E. Colégio Dom Bosco. 69 anos educando. Edição comemorativa dos 69 anos de fundação. s/e, s/d.

SANTOS, R. P. O início do ensino privado confessional na cidade de Petrolina (1920-1930). Monografia de bacharelado (História). Universidade de Pernambuco, Petrolina, 2015.

VIDAL, D. G. Por Uma Ampliação da Noção de Documento Escolar. In NASCIMENTO, M. I. M. et al. (org.). Instituições escolares no Brasil: conceito e reconstrução histórica. Campinas: Autores Associados: HISTEDBR; Sorocaba: UNISO; Ponta Grossa: UEPG, 2007. 